\title{
Corrections to: The income return to entrepreneurship: theoretical model and outcomes for Swedish regions
}

\section{Björn Hårsman ${ }^{1} \cdot$ Lars-Göran Mattsson $^{2}$ (D) Vardan Hovsepyan ${ }^{3}$}

Published online: 13 November 2018

๑) Springer-Verlag GmbH Germany, part of Springer Nature 2018

\section{Correction to: The Annals of Regional Science https://doi.org/10.1007/s00168-018-0883-4}

The original version of this article unfortunately contains an error in Appendix A. The third line contains the error, and the correct sentence is given below. "Obviously, if $X$ is Fréchet $(\beta, v)$, then $\alpha X$ is Fréchet $(\beta, \alpha v)$ for $\alpha>0$." The original article has been corrected.

The original article can be found online at https://doi.org/10.1007/s00168-018-0883-4.

$凶$ Björn Hårsman

bjorn.harsman@indek.kth.se

Lars-Göran Mattsson

lgm@kth.se

Vardan Hovsepyan

vardan.hovsepyan@indek.kth.se

1 Centre of Excellence for Science and Innovation Studies, KTH Royal Institute of Technology, Stockholm, Sweden

2 KTH Royal Institute of Technology, Stockholm, Sweden

3 Department of Industrial Economics and Management, KTH Royal Institute of Technology, Stockholm, Sweden 